Effect of Exposure Environment on Surface Decomposition of SiC-Silver Ion Implantation Diffusion Couples

Tyler J. Gerczak ${ }^{1}$, Guiqiu Zheng ${ }^{2}$, Kevin G. Field ${ }^{3 *}$, Todd R. Allen ${ }^{4}$

${ }^{1,2}$ Materials Science Program, University of Wisconsin, Madison, WI 53706, USA

${ }^{3}$ Oak Ridge National Laboratory, Oak Ridge, TN 37831, USA

${ }^{4}$ Engineering Physics Dept., University of Wisconsin, Madison, WI 53706, USA

*Formally of Materials Science Program, University of Wisconsin, Madison, WI 53706, USA

1 gerczak@ornl.gov

2 gzheng@wisc.edu

3 fieldkg@ornl.gov

${ }^{4}$ todd.allen@inl.gov

Corresponding author:

Tyler J. Gerczak

P.O. Box 2008

Oak Ridge, TN 37831 (USA)

Phone: +1 8655748766

Email: gerczaktj@ornl.gov 


\title{
Effect of Exposure Environment on Surface Decomposition of SiC-Silver Ion Implantation Diffusion Couples
}

Tyler J. Gerczak ${ }^{1}$, Guiqiu Zheng ${ }^{2}$, Kevin G. Field ${ }^{3 *}$, Todd R. Allen ${ }^{4 \wedge}$

${ }^{1,2}$ Materials Science Program, University of Wisconsin, Madison, WI 53706, USA

${ }^{3}$ Oak Ridge National Laboratory, Oak Ridge, TN 37831, USA

${ }^{4}$ Engineering Physics Dept., University of Wisconsin, Madison, WI 53706, USA

*Formally of Materials Science Program, University of Wisconsin, Madison, WI 53706, USA

1 gerczaktj@ornl.gov

2 gzheng@wisc.edu

${ }^{3}$ fieldkg@ornl.gov

${ }^{4}$ todd.allen@inl.gov

\begin{abstract}
:
$\mathrm{SiC}$ is a promising material for nuclear applications and is a critical component in the construction of tristructural isotropic (TRISO) fuel. A primary issue with TRISO fuel operation is the observed release of ${ }^{110 \mathrm{~m}} \mathrm{Ag}$ from intact fuel particles. The release of $\mathrm{Ag}$ has prompted research efforts to directly measure the transport mechanism of Ag in bulk SiC. Recent experimental efforts have focused primarily on Ag ion implantation designs. The effect of the thermal exposure system on the ion implantation surface has been investigated. Results indicate the utilization of a mated sample geometry and the establishment of a static thermal exposure environment is critical to maintaining an intact surface for diffusion analysis. The nature of the implantation surface and its potential role in Ag diffusion analysis are discussed.
\end{abstract}

Keywords: Silicon carbide, TRISO, decomposition, ion implantation 


\section{Introduction}

Silicon carbide ( $\mathrm{SiC}$ ) is a promising material for advanced nuclear systems due to its low neutron cross-section, high temperature strength, and chemical inertness [1]. The focus for SiC application in nuclear systems is primarily fuel cladding and structural core components for advanced reactor designs. $\mathrm{SiC}$ has found prominent use in the tristructural-isotropic (TRISO) particle fuel design proposed for high temperature gas cooled reactors, molten salt reactors, and as an alternative accident tolerant fuel form for light water reactors [2-4]. The current focus for TRISO fuel development is to support the advancement of the High Temperature Gas Cooled Reactor concept [2].

The general TRISO fuel construction consists of a fissile fuel kernel, surrounded by a porous carbonaceous buffer layer and successive isotropic layers of inner pyrolytic carbon, chemically vapor deposited SiC (CVD-SiC), and outer pyrolytic carbon. During operation and fuel fabrication each layer provides a specific function. The CVD-SiC layer provides the structural integrity of the fuel and serves as a primary barrier to metallic fission products (FP) not retained by the kernel. Historically, the $\mathrm{FP}^{110 \mathrm{~m}} \mathrm{Ag}$ has been observed to release from intact TRISO particles [5], while modern fuel has continued to release ${ }^{110 \mathrm{~m}} \mathrm{Ag}$ from intact particles [6]. Release of ${ }^{110 \mathrm{~m}} \mathrm{Ag}$ is suggested to be microstructurally dependent with retention observed to vary from particles with columnar CVD-SiC microstructures compared to particles with fine-grained lamellar microstructures [5]. The release of ${ }^{110 \mathrm{~m}} \mathrm{Ag}$ from intact fuel is a concern as ${ }^{110 \mathrm{~m}} \mathrm{Ag}$ in the primary coolant loop can plate out on the turbine system causing safety and maintenance concerns and an increased risk of radiation exposure.

An understanding on the silver release mechanism and release rates are necessary to improve reactor operation and reduce safety and maintenance concerns. The release rate of silver is dependent on the silver diffusion coefficient in SiC. Historically, diffusion coefficients were determined through fractional release measurements from irradiated TRISO fuel particles of ${ }^{110 \mathrm{~m}} \mathrm{Ag}$ in CVD-SiC [7-10]. The release of ${ }^{110 \mathrm{~m}} \mathrm{Ag}$ was determined primarily by out-of-pile thermal exposures with periodic measurement of the amount of released ${ }^{110 \mathrm{~m}} \mathrm{Ag}$ plated out on cold fingers or by the change in retained ${ }^{110 \mathrm{~m}} \mathrm{Ag}$ inventory 
in-particle. Diffusion coefficients were obtained by treating the measured silver release as a diffusion dependent process providing an indirect measurement of ${ }^{110 \mathrm{~m}} \mathrm{Ag}$ transport through the SiC layer. The diffusion coefficients from fractional release measurements exhibit approximately two orders of magnitude variation in reported $\mathrm{Ag}$ diffusion coefficients $\left(D_{A g}\right)$ through $\mathrm{SiC}$ TRISO layers [7-10]. The observed variation in reported $D_{A g}$ along with the indirect nature of the measurements has prompted research efforts to attempt to directly measure Ag transport in CVD-SiC to determine diffusion coefficients and understand the responsible release mechanism(s).

Recent experimental efforts have focused on ion implantation studies to understand the transport of $\mathrm{Ag}$ in $\mathrm{SiC}$ and have provided inconsistent results [11-16]. In ion implantation diffusion couples, the Gaussian implantation peak serves as the diffusion source and acts as either a constant source approximation [17] or similar to an instantaneous source approximation [11] depending on the magnitude of the peak implantation concentration. In the ion implantation diffusion couple design, diffusion is indicated by a change in the implanted profile after temperature exposure. Ion implantation experiments have shown varied diffusion behavior with broadening of the implantation peak in CVD-SiC indicating active thermal diffusion $[11,12]$ and no change in as-implanted Ag distribution indicating immobile Ag [13]. Single crystal SiC substrate studies have shown loss of the implantation dose without broadening of the Ag implantation peak $[11,15,16]$ suggesting loss of implanted Ag to the surface. Based on the ion implantation experiments and the previously summarized fractional release observations, two competing mechanisms for Ag release have been postulated in the literature: one based on microcrack transport $[14,15]$ and a second based on grain boundary (GB) diffusion $[7,8,11,13]$. Comprehensive reviews of ion implantation studies for $\mathrm{Ag}$ in $\mathrm{SiC}$ and other relevant observations of $\mathrm{Ag}$ diffusion in $\mathrm{SiC}$ have been presented by van Rooyen et al. [18] and Mahlebe [19]. These reviews provide an overview of the Ag diffusion in $\mathrm{SiC}$ behavior observed to date.

The Ag-SiC system possesses multiple experimental challenges concerning the ion implantation diffusion couple design. A primary challenge is associated with the solubility limits of Ag in SiC. The solubility limits, $S(T)$, are expected to be low at the temperatures of interest (900-1600 $\left.{ }^{\circ} \mathrm{C}\right)$ for TRISO fuel 
operation and accident conditions. The low solubility limits are inferred from the measured solubilities of high $\mathrm{Z}$ elements $(\mathrm{Z}>37)$ in single crystal $\mathrm{SiC}$ with a maximum $S(T)<1 \times 10^{17} \mathrm{at} / \mathrm{cm}^{3}$ at the temperatures of interest [20]. Low solubility limits are also expected from computational modeling of Ag-SiC defect formation energies for $\mathrm{Ag}$ substitutional, $\mathrm{Ag}$ interstitial, and $\mathrm{Ag}$-vacancy complexes in $\mathrm{SiC}$ which project $S(T) \ll<1 \times 10^{17} \mathrm{at} / \mathrm{cm}^{3}$ [21]. The slow kinetics inferred from fractional release studies and low solubility limits require high temperature exposures at prolonged times to provide a $\mathrm{Ag}$-SiC diffusion couple system with Ag concentrations above the detection limits and diffusion beyond the depth resolution for depth profiling techniques to provide insight on diffusional transport. Rutherford Backscattering Spectroscopy (RBS) and Secondary Ion Mass Spectrometry (SIMS) represent depth profiling techniques which possess adequate depth resolution and chemical sensitivity for diffusion analysis in $\mathrm{SiC}$, however, these techniques require exposed diffusion surfaces. For high temperature diffusion annealing, the exposed surfaces coupled with prolonged exposures times provides a risk of CVD-SiC surface decomposition [2227].

CVD-SiC surface decomposition is a primary concern for accurate ion implantation diffusion couple analysis as the common energies associated with the reported $\mathrm{Ag} / \mathrm{SiC}$ ion implantation studies $[12,13,15,16]$ lead to implantation peaks confined to the first few hundred nanometers of the implantation surface. Hlatshwayo et al. [16] noted the effect of surface integrity on Ag diffusion ion implantation studies in $6 \mathrm{H}-\mathrm{SiC}$ where a shift in the $\mathrm{Ag}$ profile was observed due to expected $\mathrm{SiC}$ sublimation at elevated temperatures compromising diffusion analysis. A study by Friedland et al. [11] has also noted the presence of surface decomposition above $1400^{\circ} \mathrm{C}$ in ion implantation diffusion analysis. This observed decomposition of the CVD-SiC surface would impact the near surface Ag distribution and influence interpretation of depth in diffusion analysis. As such, $\mathrm{SiC}$ decomposition at the surface of an ion implanted diffusion couples could be a contributing factor in the experimental uncertainties in the mechanisms for Ag release reported in literature. This work evaluates the effect of exposure conditions on CVD-SiC surface decomposition pertaining to ion implantation diffusion couple studies by investigating two separate ion implantation diffusion couple exposure system. The integrity of the diffusion surface for 
each system was investigated by scanning transmission electron microscopy (STEM) and related to the influence on SiC-Ag diffusion analysis techniques.

\section{Materials and Methods}

\subsection{Experimental Procedure}

\subsubsection{Diffusion Couple Designs}

CVD-SiC substrates were ion implantation with $\mathrm{Ag}^{+}$to investigate the surface integrity after thermal exposure. Commercial CVD-SiC substrates from Rohm and Haas were mechanically polished to a roughness, $\mathrm{R}_{\mathrm{a}}$, of $<10 \mathrm{~nm}$ as measured by optical profiliometry using a Zygo New View Optical Profilometer. The polished CVD-SiC substrates were implanted with $400 \mathrm{keV} \mathrm{Ag}$ ions to a fluence of $5 \times 10^{14} \mathrm{Ag}^{+} / \mathrm{cm}^{2}$ and $2 \times 10^{16} \mathrm{Ag}^{+} / \mathrm{cm}^{2}$ by the Michigan Ion Beam Laboratory (MIBL) through the Advanced Test Reactor National Scientific User Facility (ATR NSUF). Ion implantations were performed at $300^{\circ} \mathrm{C}$ to increase the critical dose to amorphization during implantation preventing amorphization of the CVD-SiC implantation layer [28]. Implantation resulted in a near Gaussian Ag concentration profile with a maximum peak concentration at approximately $150 \mathrm{~nm}$. Following ion implantation, an approximately $210 \mathrm{~nm}$ diamond-like-carbon (DLC) layer was deposited on the implantation surface using plasma source ion implantation deposition at the University of Wisconsin-Madison. The DLC layer serves to contain the implantation dose and protects the implantation interface during thermal exposure while still being thin enough to perform SIMS and RBS analysis.

Ion implanted diffusion couples were exposed to elevated temperature to investigate the integrity of the implantation surface for $\mathrm{Ag} / \mathrm{SiC}$ diffusion analysis applications. Two different thermal exposure systems were investigated in this study. The first exposure system was a high temperature-vacuum anneal. The samples were exposed under a vacuum of $3 \times 10^{-5}$ torr in a $\mathrm{W}$-mesh furnace capable of temperatures up to $2000{ }^{\circ} \mathrm{C}$ with the furnace temperature controlled and monitored by a thermocouple positioned in the furnace hot zone. The vacuum of the system provided a low $\mathrm{pO}_{2}$ environment to limit oxidation of the DLC layer and potential interaction with the implantation surface. The as-implanted DLC coated Ag implanted CVD-SiC substrates were placed on a graphite block and surrounded by a 
CVD-SiC box in an attempt to limit CVD-SiC thermal decomposition. The $\mathrm{W}$-mesh furnace required a $1000{ }^{\circ} \mathrm{C} /$ hour ramp and cool rate, which prevented the ability to quench the samples after thermal exposure. Ion implantation diffusion couples were exposed in the $\mathrm{W}$-mesh vacuum furnace to temperatures up to $1500{ }^{\circ} \mathrm{C}$.

The second thermal exposure system utilized a self-contained, fused quartz ampoule exposure method. In this approach the DLC-coated ion implantation sample is mated with a polished CVD-SiC sample and secured with graphite paste. The introduction of graphite paste to the system is not expected to influence the exposure comparison as the W-mesh system contains graphite components in the hot zone as well. The mated sample was then inserted in a $6 \mathrm{~mm}$ inner diameter $13 \mathrm{~mm}$ outer diameter fused quartz tube with one end sealed by thermal bonding with an inserted $5.5 \mathrm{~mm}$ diameter fused quartz rod under vacuum. The vacant area was backfilled with coarse, approximately $0.5 \mathrm{~mm}$ diameter, SiC powder to serve as excess sacrificial $\mathrm{SiC}$ to limit potential oxidation and decomposition of the surface. A $50 \mathrm{~mm}$ long by $5.5 \mathrm{~mm}$ diameter fused quartz rod was then inserted in the sample tube and the system was pumped down to rough vacuum and backfilled with ultra high purity Ar. This pump and purge process was repeated five times and the sample was then sealed under vacuum. A schematic of this sample system is shown in Figure 1. The mated SiC/DLC/SiC geometry and self-contained system protected the implantation surface and allowed for an establishment of equilibrium partial pressures of the volatile $\mathrm{Si}$ species, pSi and pSiO, limiting CVD-SiC surface decomposition. The self-contained design also allows the sample to be inserted at temperature and removed from temperature with a rapid quench. This approach limited the diffusion contributions from heating and cooling which more closely reflects the $\mathrm{Ag}$ distribution observed at temperature by limiting back-diffusion and precipitation during cooling. The fused quartz ampoules were then annealed in a MTI GSL 1600X-80 tube furnace. The temperature was monitored by monitored by an external calibrated thermocouple positioned in the center of the tube furnace hot zone. Thermal exposures were carried out at $1500^{\circ} \mathrm{C}$ for up to 10 hours. 


\subsubsection{STEM Analysis}

Samples for STEM investigations were fabricated with a focused ion beam (FIB) lift-out technique. FIB lift-outs assured preservation of the DLC layer and Ag implantation zone. Cross- sectional FIB lift-out samples were fabricated using a Zeiss 1540XB Crossbeam FIB/SEM at the University of Wisconsin - Madison, Materials Science Center (UW-MSC). Regions of interest were capped by $\mathrm{Ga}^{+}$ion beam deposition of $\mathrm{C}$ prior to trenching to minimize FIB induced damage. Electron transparent specimens were finished using a $5 \mathrm{kV} \mathrm{Ga}^{+}, 200 \mathrm{pA}$ beam to remove $\mathrm{Ga}$ contamination and ion beam induced damage from the FIB lift-out lamella surface.

FIB lift-out specimens were investigated using a FEI Titan S-TWIN D2080 CEOS Cs corrected (S)TEM operated in STEM mode with an accelerating voltage of $200 \mathrm{keV}$ at the UW-MSC. Energy dispersive X-ray spectroscopy (EDS) was conducted using EDAX acquisition hardware and FEI's TEM Imaging and Analysis (TIA) software. The CEOS probe aberration corrector was not optimized as highresolution imaging was not required for imaging and microchemical analysis. Imaging was completed using annular dark field (ADF) imaging which is prominently diffraction contrast dominated. Microchemical analysis was conducted using spectrum imaging. Spectrum images acquisition was designed to replicate 3 successive line scans along the same interface of interest. 2D EDS spectrum images were acquired with a region of interest size of $500 \mathrm{~nm} \times 6 \mathrm{~nm}$ containing $300 \times 3$ pixels, a 1500 ms dwell time per pixel and drift corrected every 23 pixels and simultaneous ADF signal acquisition.

The C, O, and Si concentrations were quantified using the Cliff-Lorimer approach [29] assuming stoichiometric $\mathrm{SiC}$ with .003 wt. \% O impurity. Experimentally determined 'k-factors' were calculated based on EDS spectrums obtained in the non-implanted region of the crystalline SiC substrate. Areas with significant decomposition exhibited total counts for individual pixel spectrums below limits to obtain quantitative measurements. Therefore, the results presented here are presented as qualitative and only the relative ratios in composition variations in these areas should be utilized in the analysis. Line profiles were calculated by averaging the pixel-determined compositions perpendicular to the implantation surface. Error was calculated based on one standard deviation of the mean. 


\section{Results}

Figure 2 shows an overlay of the simulated $\mathrm{Ag}$ ion range and relevant damage profile in displacements per atom (dpa) determined by SRIM 2008 [30] along with the measured SIMS Ag depth profile for the $5 \times 10^{14} \mathrm{Ag}^{+} / \mathrm{cm}^{2}$ as-implanted condition, these profiles are overlaid on an ADF micrograph. SIMS analysis of the $2 \times 10^{16} \mathrm{Ag}^{+} / \mathrm{cm}^{2}$ as-implanted samples yielded detector saturation, as such, continued analysis was not pursued as the conditions did not provide acceptable samples for future diffusion analysis. SIMS depth profiles of the as-implanted substrate were obtained by the Institute for Critical Technology and Applied Science at Virginia Tech University on a Cameca IMS 7f Geo magnetic sector SIMS using a $5 \mathrm{keV}$ primary $\mathrm{O}_{2}^{+}$sputtering beam. Sputtering rates were determined from the SIMS crater depth using a Zygo New View Optical Profilometer. SRIM simulations have been observed to underestimate the ion range in SRIM simulations for heavy ions in SiC to correct for this, a scaling factor was instituted to account for the difference in range observed between the measured SIMS and SRIM simulations [31]. From Figure 2 the implantation peak presents a near Gaussian distribution and no apparent restructuring is observed in the as-implanted region. The retention of microstructure was identified in the underlying ADF image in Figure 2, which is dominated by diffraction contrast, by no change in diffraction contrast, indicative of a microstructure change from amorphization, and by stacking faults, twinning, and grain boundaries present across the crystalline substrate and implantation zone. The depth profiles also indicate a majority of the implantation dose is contained in depths ranging from 0-300 $\mathrm{nm}$ of the implantation surface.

Samples from each exposure system, exposed to $1500^{\circ} \mathrm{C}$ for 10 hours, were investigated by STEM to determine the integrity of the ion implantation interface after thermal exposure. STEM analysis indicated significant variation in the surface behavior of the two diffusion couple exposure techniques. Figure 3 shows ADF micrographs of each exposure condition and as-implanted condition. From Figure 3, the fused quartz ampoule exposure maintains an intact implantation surface with an appearance identical to the as-implanted reference sample with the exception of Ag-rich precipitates decorating the implantation region. This observation confirms the mated-geometry, static environment, fused quartz 
ampoule design limits CVD-SiC surface decomposition and preserves the implantation zone. In comparison, the substrate exposed in the $\mathrm{W}$-mesh vacuum furnace showed a secondary phase extending into the CVD-SiC bulk beneath the DLC layer. The secondary phase extends approximately $150 \mathrm{~nm}$ into the CVD-SiC substrate and has consumed the Ag implantation layer as Ag precipitates are observed within the second phase beneath the DLC layer. Inset I in Figure 3B shows a close up of the $\mathrm{SiC} /$ secondary phase interface, identifying a significant change in morphology from the SiC substrate, while insets II and III show selected area diffraction patterns of the SiC substrate and secondary phase, confirming a change in structure. The DLC layer appears to be intact as no significant dimensional change was observed, with a constant layer thickness of approximately $210 \mathrm{~nm}$ observed before and after thermal exposure in both exposure systems. It is however, likely that the DLC layer partially graphitized as graphitization occurs above $1100^{\circ} \mathrm{C}$ for DLC exposed under vacuum [32]. Any volume change due to graphitization would be dependent on the initial density of the DLC layer and the change in $\mathrm{sp}^{3}$ and $\mathrm{sp}^{2}$ bonding after graphitization. In each exposure system and the as-implanted substrate, grain boundaries and stacking faults were observed, suggesting no significant microstructural variations in the CVD-SiC account for the observed secondary phase formation. The features associated with changing contrast perpendicular to the implantation surface in the W-mesh exposure lift-out sample, Figure 3B, are associated with FIB curtaining effects due the irregular CVD-SiC/secondary-phase interface.

EDS analysis was employed to determine the relative $\mathrm{Si}, \mathrm{C}$, and $\mathrm{O}$ concentrations of the secondary phase on the ion implanted interface. Figure 4 shows 1D microchemical information from EDS analysis derived from binning the 2D spectrum maps, the line scans extend from the start of the DLC layer to $500 \mathrm{~nm}$ into the CVD-SiC bulk. From Figure 4 it is apparent that the secondary phase is primarily $\mathrm{C}$ with localized $\mathrm{Si}$ concentrations. Trace $\mathrm{O}$ is also observed to coincide with the localized $\mathrm{Si}$ concentrations in the secondary phase and at the CVD-SiC/secondary phase boundary. The EDS line scan confirms the secondary layer is approximately $150 \mathrm{~nm}$ in thickness and shows a $\mathrm{C}$ and $\mathrm{Si}$ gradient at the CVD-SiC/secondary phase interface, indicating a variation in $\mathrm{Si}$ and $\mathrm{C}$ concentrations at the CVD$\mathrm{SiC} /$ secondary-phase interface. 


\section{Discussion}

The observed change of surface structure in the W-mesh furnace exposure is indicative of high temperature surface decomposition of the CVD-SiC implantation layer. The consistent thickness of the DLC layer indicates the C-rich secondary phase growth layer is formed by the decomposition of the CVD-SiC and not from changes in the DLC layer. This is further corroborated by the observation of $\mathrm{Ag}$ precipitates in the secondary phase layer implying the decomposition layer grew from the CVD-SiC-DLC interface into the CVD-SiC substrate and partially consumed the Ag implantation zone. The $\mathrm{Si}$ and $\mathrm{C}$ concentration gradient indicates the decomposition is facilitated by transport of $\mathrm{Si}$ to the surrounding system. The presence of Ag in the decomposition layer indicates the initial and boundary conditions necessary to conduct accurate diffusion analysis have been compromised, as the initial substrate no longer exists. The nanometer scale nature of the Ag implantation source highlights the surface sensitivity of the ion implantation approach and need to maintain a quality implantation surface. The fused quartz ampoule design exhibited a sharp carbon/CVD-SiC transition and no significant decomposition layer indicating the integrity of the interface was maintained during thermal exposure. This confirms a thermal exposure system can be implemented that preserves the implantation surface $\mathrm{SiC}$ substrate allowing for high temperature Ag diffusion studies.

The decomposition of the Ag ion implanted CVD-SiC substrate in the W-mesh furnace exposure system is similar to the observed decomposition of exposed CVD-SiC under vacuum, where the decomposition is due to a sublimation reaction with Si sublimed from the CVD-SiC surface leaving a carbide-derived-carbon (CDC) structure behind [22-27]. These carbide-derived-carbon structures show elongated features along the direction of the decomposition layer growth [22-27] and similar features are observed in the W-mesh exposure system decomposition layer, Figure 3B-I. The sublimation reaction can occur by evolving either $\mathrm{Si}$ or $\mathrm{SiO}$ from the surface [27] and is believed to be catalyzed by trace $\mathrm{O}_{2}$ concentrations [22-27]. The volatile Si species formed at the reaction surface can then move by vapor transport away from the reaction as the decomposition phase is not fully dense [23]. In the decomposed CVD-SiC substrate with the DLC coating $\mathrm{Si}$ or $\mathrm{SiO}$ transport would also have to occur across the DLC 
layer. DLC thin films have also been shown to be gas permeable $[33,34]$ which would allow for possible vapor transport across the layer facilitating the reaction, while atomistic diffusionacross the layer is also possible at elevated temperatures [35]. It is expected that the system vacuum over the CVD-SiC surface does not allow for the establishment of a partial pressure for the volatile Si species evolved from the CVD-SiC surface even with the presence of a sacrificial CVD-SiC vessel. The EDS analysis of the secondary phase indicates localized increases in trace $\mathrm{O}$ at the CVD-SiC/secondary-phase interface and at the areas of increased $\mathrm{Si}$ in the secondary decomposition phase. This observation further indicates the decomposition may be catalyzed by oxidation of the CVD-SiC implantation surface. This suggests that the expected low $\mathrm{pO}_{2}$ in the $\mathrm{W}$-mesh environment, relative to the fused quartz ampoule system, was not sufficient to limit decomposition and maintain an intact implantation surface. In the fused quartz ampoule design the effect of CVD-SiC decomposition were minimized as the static environment allowed for an establishment of an equilibrium $\mathrm{pSi}$ and $\mathrm{pSiO}$. Additionally, the $\mathrm{SiC}$ powder provides excess $\mathrm{SiC}$ surface area and served as a sacrificial $\mathrm{SiC}$ source minimizing the potential for $\mathrm{SiC}$ decomposition.

The formation of the C-rich secondary phase beneath DLC layer indicates the importance of the exposure conditions for accurate diffusion experimental design and analysis. Depending on the analysis technique used for determination of the Ag/CVD-SiC depth profile, potential misinterpretations of the change in the ion implantation impurity concentration as a function of depth are possible. In SIMS analysis, the signal is a direct measure of the substrate in question and would identify the loss of surface integrity and indicate the consumption of the Ag implantation layer by the C-rich, secondary phase decomposition front. However, RBS analysis requires prior knowledge on the substrate in question to fit the acquired energies to proper channels. The presence of an unknown thickness of a Si-depleted phase or non-uniform internal interfaces, such as the observed decomposition front/SiC substrate interface, could lead to misinterpretation of the RBS spectrum. The nanometer scale of the expected diffusion lengths and implantation depths, highlights the importance in understanding and maintaining a quality interface as nanometer scale changes is surface features may manifest as changes the implanted species depth profiles. Decomposition of the implantation surface can also limit the temperature range of interest 
for diffusion studies. Previous investigations have primarily focused on temperatures below $1500^{\circ} \mathrm{C}[11-$ 16] with surface decomposition noted at approximately $1400^{\circ} \mathrm{C}[11,16]$. Investigation of temperatures above $1500^{\circ} \mathrm{C}$ may be attainable by utilizing a system which maintains an equilibrium partial pressure of the volatile Si species and protects the implantation surface allowing for expanded understanding of Ag diffusion in CVD-SiC.

The observation of Si loss from the implantation surface implies the potential for Ag loss through a similar mechanism. In the ion implantation diffusion couples, if an equilibrium Ag vapor pressure is not established above the ion implantation surface, $\mathrm{Ag}$ loss to the system atmosphere could occur. Observed Ag loss at the implantation surface can be explained by desorption as shown by Xiao et al. [15] and may be a dominant factor contributing to near surface Ag redistribution in implanted SiC. This effect may be significant at temperatures of interest for $\mathrm{Ag}$ release, $900-1600^{\circ} \mathrm{C}$, due to significant increase in $\mathrm{pAg}$ above the melting temperature of $\mathrm{Ag}, T_{m} \sim 962^{\circ} \mathrm{C}[36]$.

\section{Conclusions}

The challenges associated with maintaining surface integrity during thermal annealing can be attributed to the exposure system. Failure to maintain a quality surface through the utilization of a proper exposure system leads to changes in substrate composition and potential non-uniform loss of the impurity diffusant to the atmosphere which can introduce error in diffusion analysis. The potential for error was indicated as an approximately $150 \mathrm{~nm}$ decomposition, secondary phase layer was observed to consume a portion of the implantation region in the vacuum anneals. The ability to maintain a proper diffusion substrate for high temperature ion implantation diffusion couple analysis was demonstrated through the use of mated-geometry, static diffusion couple exposure system which limits the loss of volatile Si species from the SiC substrate.

\section{Acknowledgements}

A portion of this research utilized National Science Foundation (NSF) supported shared facilities at the University of Wisconsin. This work supported by the US DOE, Office of Nuclear Energy Nuclear Energy University Program (NEUP), award no. 11-2988 and by the US DOE, Office of Nuclear Energy 
under DOE Idaho Operations Office Contract DE-AC07-051D14517, as part of an ATR-NSUF

experiment. The authors would also like to thank Dr. Ovidiu Toader for conducting the Ag implantations at the MIBL and Dr. Jerry Hunter for conducting the SIMS analysis at ICTAS at Va. Tech.

\section{References:}

[1] L. L. Snead, T. Nozawa, Y. Katoh, T. S. Byun, S. Kondo, D. A. Petti, J. Nucl. Mater. 371, (2007) 329-377

[2] D. Petti, J. Maki, J. Hunn, P. Pappano, C. Barnes, J. Saurwein, S. Nagley, J. Kendall, R. Hobbins, JOM, 62, 9, (2010) 62-66

[3] R.S. Sen, M.A. Pope, A.M. Ougouag K. Pasamehmetoglu, "Assessment of possible cycle lengths for fully ceramic micro encapsulated fuel-based light water reactor concepts," PHYSOR 2012 Advances in Reactor Physics - Linking Research, Industry, and Education, April 2012

[4] D.T. Ingersoll, C.W. Forsberg, L.J. Ott, D.F. Williams, J.P. Renier, D.F. Wilson, S.J. Ball, L. Reid, W.R. Corwin, G.D. Del Cul, P. F. Peterson, H. Zhao, P.S. Pickard, E.J. Parma, M. Vernon, ORNL/TM-2004/104

[5] D.A. Petti, J. Buongiorno, J. T. Maki, R. R. Hobbins and G. K. Miller, Nucl. Eng. Des., 222, 2-3 (2003) 281-297.

[6] P.A. Demkowicz, J.D. Hunn, R.N. Morris, J.M. Harp, P.L. Winston, C.A. Baldwin, F.C. Montgomery, "Preliminary results of post-irradiation examination of the AGR-1 TRISO fuel compacts," Proceedings of the 6th International Topical Meeting on High Temperature Reactor Technology, Tokyo, Japan, October 28-November 1, 2012, HRT2012 (2012).

[7] H. Nabielek, P. E. Brown, P. Offerman, Nucl. Tech., 35, 2 (1977) 483-493.

[8] W. Amian, D. Stöver, Nucl. Tech. 61, 3 (1983) 475-486.

[9] K. Verfondern, R.C. Martin, R. Moormann, Jül -2721 Forschungszentrum Jülich GmbH, January (1993).

[10] H. Nabielek, "SiC for Fuel," 33rd ICACCS Discussion group of Symposium 10 on silicon carbide, Daytona Beach, FL (2009).

[11] E. Friedland, J.B. Malherbe, N.G. van der Berg, T. Hlatshwayo, A.J. Botha, E. Wendler, W. Wesch, J. Nucl. Mater. 389, 2 (2009) 326-331.

[12] E. Friedland, N.G. van der berg, J.B. Malherbe, J.J. Hancke, J.R.N. Barry, E. Wendler, W. Wesch, J. Nucl. Mater., 410, (2011) 24.

[13] H.J. MacLean, R.G. Ballinger, L.E. Kolaya, S.A. Simonson, N. Lewis, M.E. Hanson, J. Nucl. Mater. 357 (2006) 31.

[14] H. J. MacLean, "Silver Transport in CVD SiC," PhD Thesis, Massachusetts Institute of Technology 
(2004).

[15] X.Y. Xiao, Y. Zhang, L.L.Snead, V. Shutthananddan, H.Z. Xue, W.J. Weber, J. Nucl. Mater. 420 (2012) 123-130.

[16] T.T. Hlatshwayo, J.B. Malherbe, N.G. van der Berg, L.C. Prinsloo, A.J. Botha, E. Wendler, W. Wesch, J. Nucl. Mater, 389 (2009) 326.

[17] S. M. Myers, J. Vac. Sci. Technol. 15 (1978) 1650.

[18] I.J. van Rooyen, M.L. Dunzik-Gougar, P.M. van Rooyen, Nucl. Eng. Des., In Press

[19] J.B. Malherbe, J. Phys. D: Appl. Phys., 46 (2013) 473001.

[20] O. Madelung, U. Rössler, and M. Schulz, (editors), "LB Volumes III/22B-41A2b: silicon carbide (SiC), solubility of impurities." Springer Materials - The Landolt-Börnstein Database

[21] D. Shrader, S. M. Khalil, T. Gerczak, T. R. Allen, A. J. Heim, I. Szlufarska, D. Morgan, J. Nucl. Mater. 408 (2011) 257-271.

[22] M. Kusunoki, M. Rokkaku, T. Suzuki, Appl. Phys. Lett. 71 (1997) 2620.

[23] M. Kusunoki, T. Suzuki, K. Kaneko, M. Ito, Philos. Mag. Lett. 79(4) (1999) 153-161.

[24] W. Norimatsu, M. Kusunoki, Physica E 42(4) (2010) 691-694.

[25] J. Hass, W.A. De Heer, E.H. Conrad, J. Phys. Condens. Matter 20 (2008) 323202.

[26] Z.G. Cambaz, G. Yushin, S. Osswald, V. Mochalin, Y. Gogotsi, Carbon 46(6) (2008) 841-849.

[27] Z.G. Cambaz, G. Yushin, V. Mochalin, Y. Gogotsi, J. Mater. Res, 28(7) (2013) 952-957.

[28] L.L. Snead, S.J. Zinkle, J.C. Hay, M.C. Osborne, Nucl. Instrum. Meth. B 141 (1998) 123-132.

[29] D.B. Williams, C. B. Carter, "Transmission electron microscopy: a textbook for materials science" Springer, $2^{\text {nd }}$ Ed. (2009).

[30] J.F. Zeigler, SRIM-2008, v. 2008.40, http://srim.org

[31] Y. Zhang, I. Bae, K. Sun, C. Wang, M. Ishimary, Z. Zhu, W. Jiang, W.J. Weber, J. Appl. Phys., 105 (2009) 104901-12.

[32] J. Robertson, Mater. Sci. and Eng. R 37, (2002) 129-281.

[33] J.M. Lackner, C. Meindl, C. Wolf, A. Fian, C. Kittinger, M. Kot, L. Major, C. Czibula, C. Teichert, W. Waldhauser, A.M. Weinberg, E. Frohlich, Coatings, 3, (2013) 268-300.

[34] N.J. Ianno, T.J. Makovicka, Rev. Sci. Instrum., 70, 4 (1999) 2072-2073.

[35] H. Kroger, C. Ronning, H. Hofsass, P. Neumaier, A. Bergmaier, L. Gorgens, G. Dollinger, Diam. Relat. Mater., 12 (2003) 2042-2050.

[36] W.M. Haynes (editor), "CRC handbook of chemistry and physics," 94th Edition, Taylor and Francis Group, Boca Raton, FL 2013. 


\section{Tables and Figures:}

Mated Ion

Implantation Sample

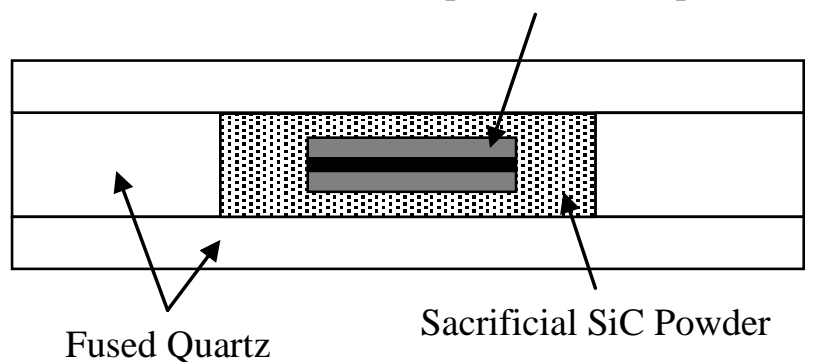

Figure 1: Schematic of ion implantation diffusion couple self-contained fused quartz ampoule thermal exposure set up.

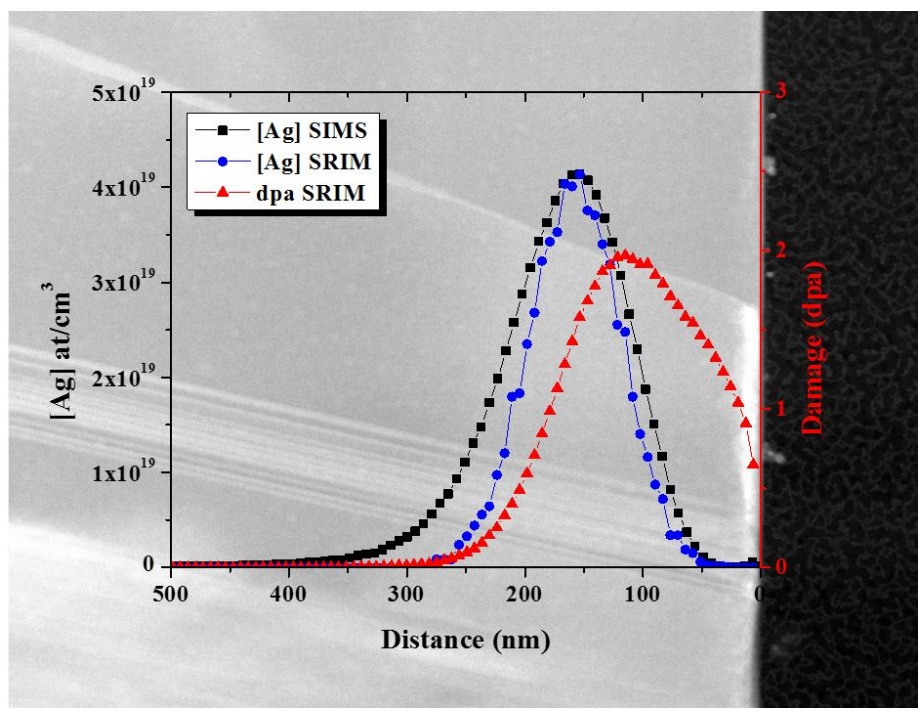

Figure 2: Overlay of SRIM ion range, SIMS Ag depth profile, and damage profile from SRIM on ADF micrograph of the diffusion interface, no change in contrast is observed in the implantation regime. 


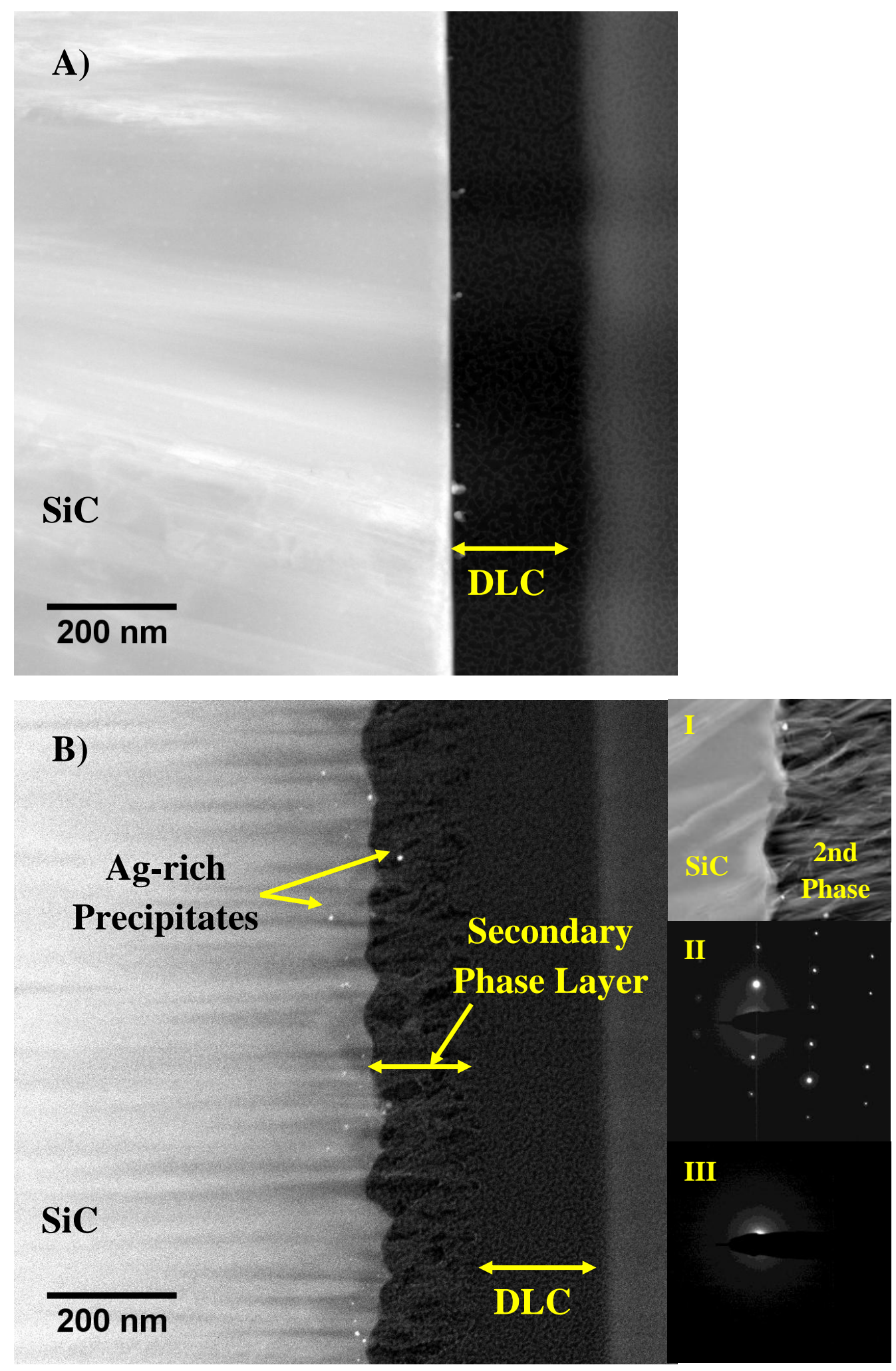




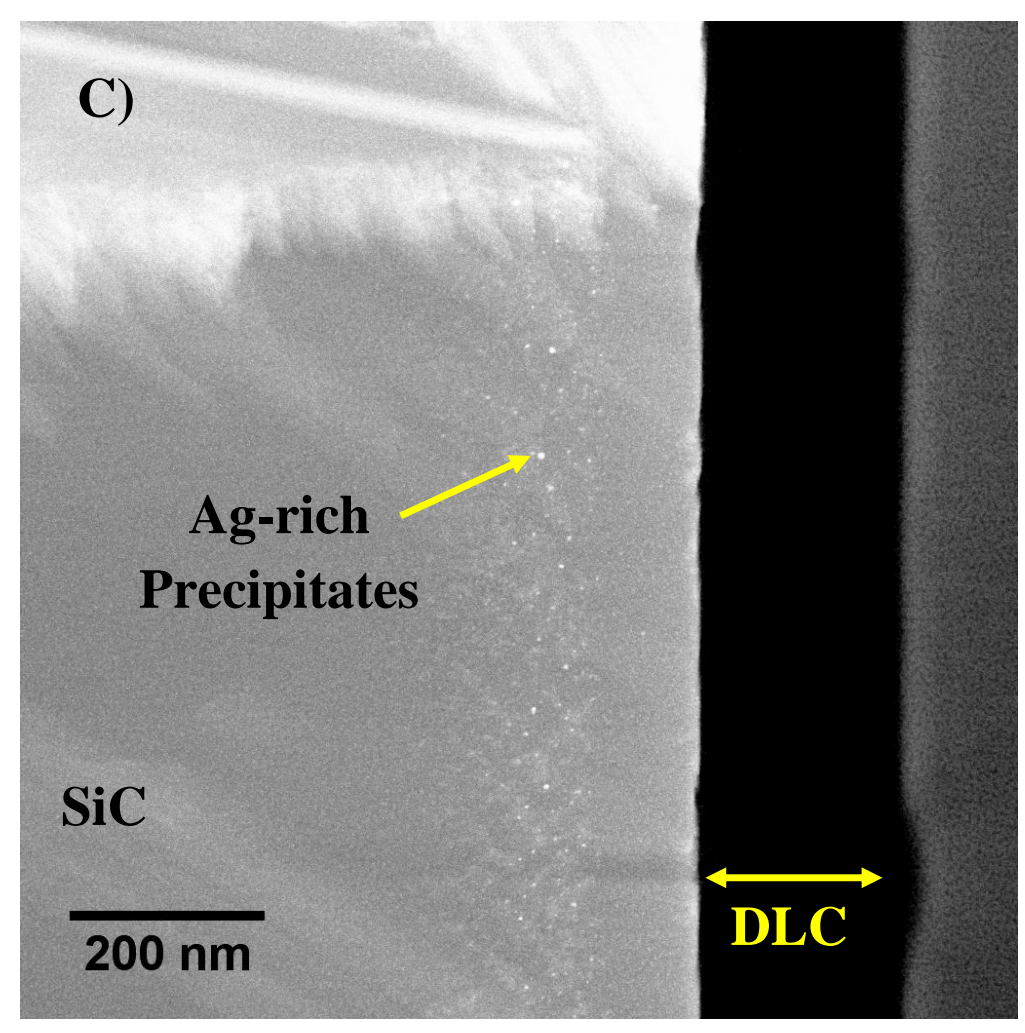

Figure 3: ADF micrographs of the diffusion interface the A) as-implanted CVD-SiC, B) ion implantation diffusion couple exposed to $1500^{\circ} \mathrm{C}$ for 10 hours in the $\mathrm{W}$-mesh vacuum furnace, where inset I shows close up of secondary phase/CVD-SiC interface, inset II shows a selected area diffraction pattern of the

$\mathrm{SiC}$ substrate near the (122) zone axis and inset III shows a selected area diffraction pattern of the secondary phase, and C) ion implantation diffusion couples exposed in the self-contained ampoule, indicating the CVD-SiC substrate, secondary phase layer, and DLC coating. 


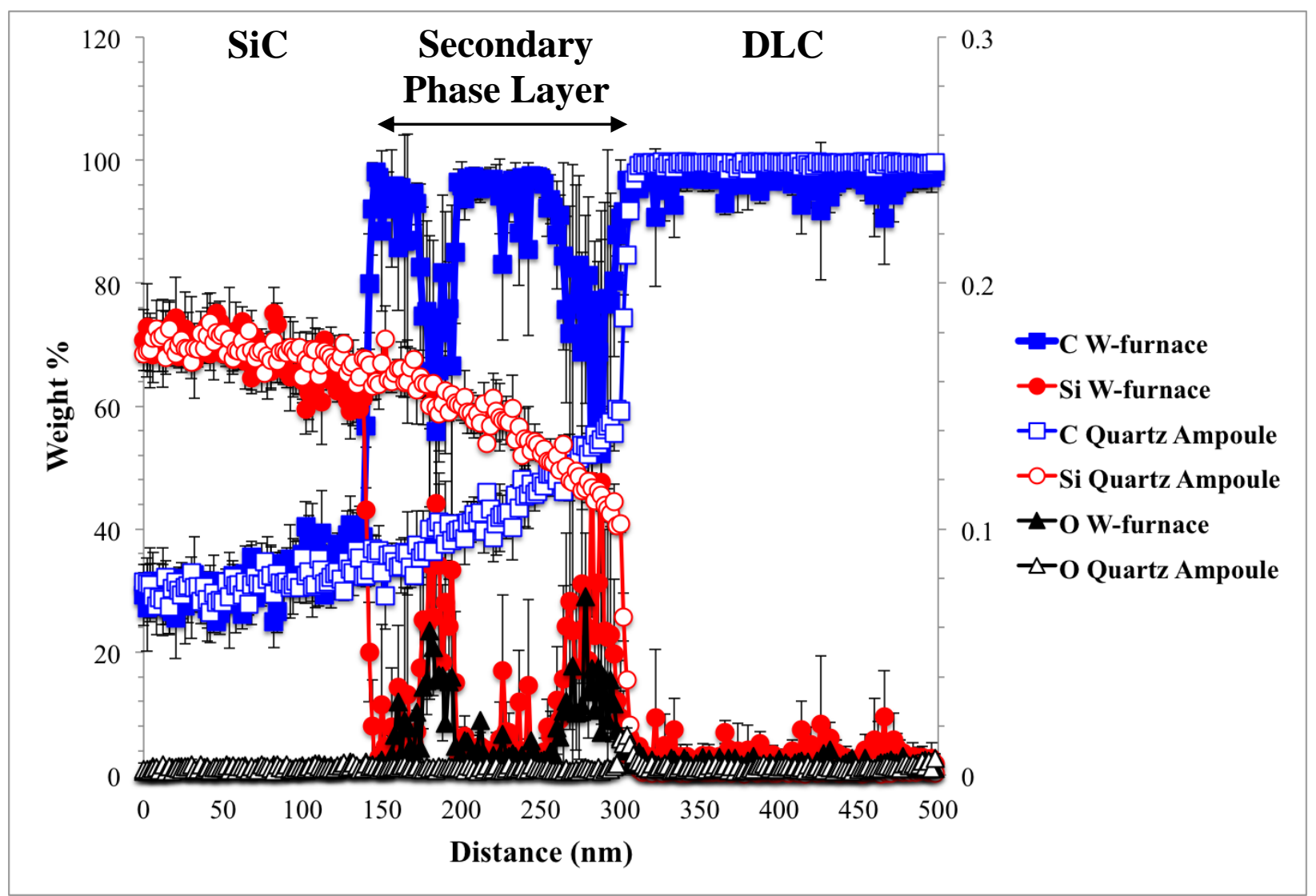

Figure 4: 1D EDS line profile of qualitative $\mathrm{Si}, \mathrm{C}$, and O composition in wt. $\%$ for $1500^{\circ} \mathrm{C} 10 \mathrm{Hours} \mathrm{W-}$ mesh vacuum furnace exposure (closed) and static fused quartz ampoule exposure (open), here the $\mathrm{C}$ concentration is presented on the secondary axis on the right, the plot terminates at $500 \mathrm{~nm}$ indicating the end of the DLC thickness, and variation in $\mathrm{Si}$ and $\mathrm{C}$ composition indicates thickness of secondary phase layer. Wt.\% is presented in lieu of at. \% to limit overlap on the graph of Si and C. 